Trade News is supplied as a service to the reader and does not imply endorsement by the BDJ. Normal and prudent research should be exercised before purchase or use of any product mentioned. Please send trade news information and illustrations to Sarah Murnal at the BDJ, 64 Wimpole Street, London WIM 8AL.

\section{Really glovely!}

Brosch direct have introduced the Bodyguards Extra Touch powder-free polymer coated latex glove to complement their existing Bodyguards glove range.

The gloves are manufactured to create a soft and flexible glove for a sensitive feel and ultimate grip.

This new glove is powder-free and also offers the following benefits:

- Polymer coated to provide a barrier between latex and user with very low protein levels.

- Chlorine free to help eliminate odour and reduce potential allergens to the user with reduced harm to the environment.

The gloves are priced at $\mathfrak{£} 2.35$ per box of 100 gloves. To find out more, contact Brosch on Tel: 01733230230 or Fax: 01733230333.

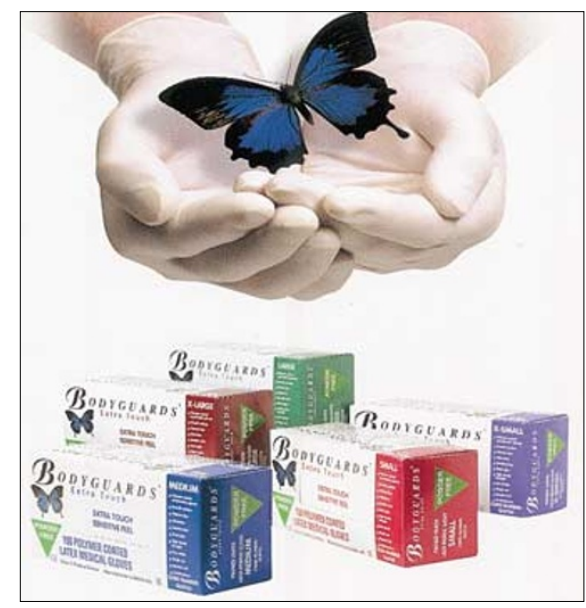

Reader response number:

051

\section{Apology}

The BDJ apologise to Bien Air UK for the incorrect text published in the BDJ Dentistry 2000 supplement. The text should read as follows:

Bien Air's electric micromotor - the MC.3, with or without light, is capable of high quality performance at speeds ranging from 100-200,000 rpm without loss of torque. To take full advantage of this motor the slow-speed electronic board

\title{
Word of mouth
}

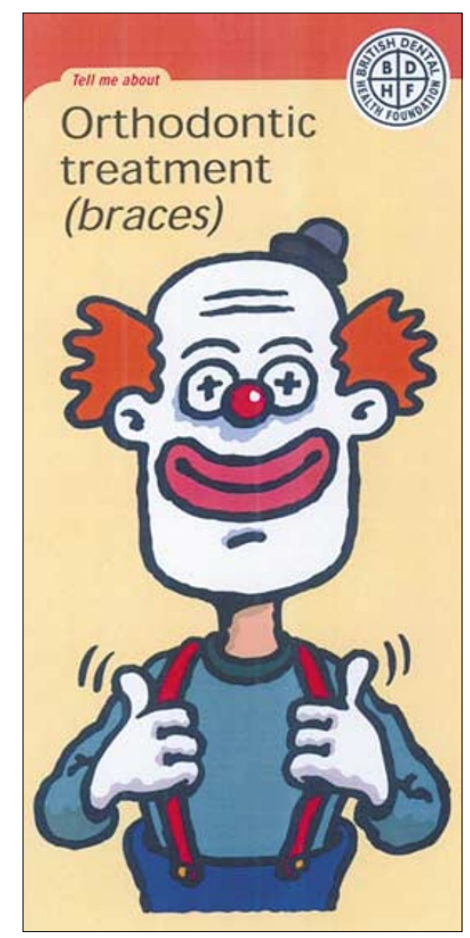

New brochures from the British Dental Health Foundation have been awarded a 'plain English approved' logo. This means that they have been checked by The Word Centre for clarity of language and layout.

The Foundation re-launched its 'Tell Me About' leaflets two years ago under a new design and easier to understand question and answer format. Since then, the series has grown and there is now a total of 20 leaflet titles and six brochures.

The Word Centre says it aims to make sure the language and layout of the leaflets are clear and easy to follow. When publications meet their standard they award the 'plain English approved' logo.

The five new titles - Tell me about jaw problems and headaches, Caring for my teeth, Cosmetic treatment, My fear of the dentist and Orthodontic treatment (braces) - join the re-vamped Dentures brochure to bring the full range into the same format.

The new brochures are available in packs of 50 priced $\mathfrak{£} 9.38$ to BDHF members and $\mathfrak{E} 12.50$ to non members. For more details telephone 01788546365 .

Reader response number:

052

must be fitted which comes with a digital speed readout, allowing operation between $100 \mathrm{rpm}$ and the basic motor speed of 4,000 rpm. For speeds in excess of $40,000 \mathrm{rpm}$, speed-increasing handpieces can be used.

In addition, Bien Air offer handpieces straight and contra-angle — including prophy and implantology models and high-speed turbines - Bora S.36/S36L and Prestige S.32/S32L.

For surgical use, Bien Air have the ORLE-92 Drill System and new Chiropro tabletop implantology unit and for the laboratory, the air-driven TD793 Turbine and the Technobox 810 for both laboratory and domiciliary use.

Reader response number:

053

\section{Dentalguide}

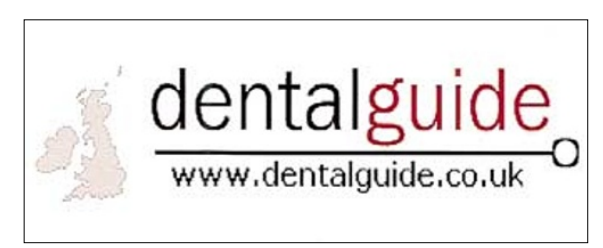

A UK and Ireland Internet dental guide has just been set up. The 'dentalguide' web site is designed for dentists, staff, technicians and the dental trade. There are links to over 500 web sites including practices, suppliers and manufacturer's web sites. Laboratories, academic and dental organi- sations are also included. There is also a classified ads section and a specialist dental bookshop.

The guide is designed to be comprehensive and easy to navigate and dentists or organisations may request a link to their site to be added.

Use of the guide is free and no registration is required. To view the site visit www.dentalguide.co.uk

Reader response number:

054

\section{Healthy teeth are at hand}

An easy to read dental leaflet for patients called 'Open Wide! Simple Steps to Healthy Teeth' has been launched by SmithKline Beecham. This eye-catching leaflet gives information on the causes of tooth decay and tooth erosion and provides the patient with practical steps to help keep their teeth - and those of their children - healthy.

Each leaflet contains a 20 pence off coupon to encourage patients to purchase Ribena Toothkind - which is scientifically proven to minimize tooth erosion.

Dentists can get free copies of the leaflet together with a free surgery leaflet holder from their SmithKline Beecham representative or, freephone 08000963 666.

Reader response number:

055 
Trade News is supplied as a service to the reader and does not imply endorsement by the BDJ. Normal and prudent research should be exercised before purchase or use of any product mentioned.

Please send trade news information and illustrations to Sarah Murnal at the BDJ, 64 Wimpole Street, London W1M 8AL.

This issue, the Trade News focus is practice management and computer software. Our regular 'what's new' section, for new trade products and services, appears on page 460 .

\section{How to Please your patients}

Computerised Information Technology Ltd (CIT) based in Milton Keynes has been awarded the contract to supply the Integrated Clinic Management System (ICMS) to the Soyombo Dental Centre in Bletchley, Milton Keynes.

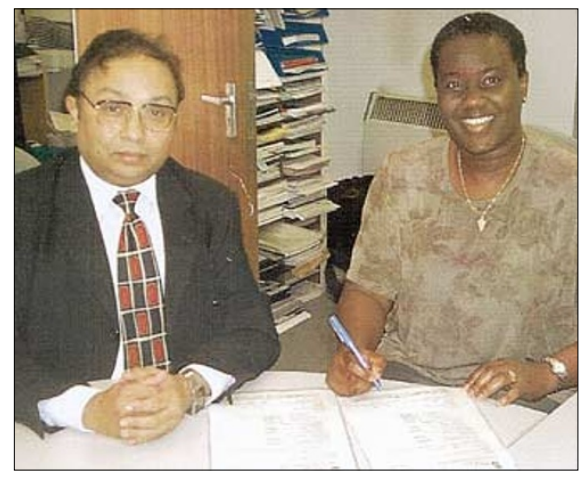

The system helps improve patient care, reduces administrative costs and patient treatment time and uses digital film-less radiography. Patients will benefit from a faster response, better treatment planning and interactive feedback.

For further details e-mail Mr Sood at Computerised Information Technology Ltd onscsood@cituk.com or telephone Dr Soyombo at 01908630169.

Reader response number:

056

\section{Cries for help!}

More dentists are calling the DDU's 24hour helpline for dento-legal advice than ever before. Calls to the helpline reached over 6000 last year, up from 5000 in 1998 an increase of $20 \%$.

The DDU believes the increase reflects the dento-legal climate of rising litigation, complaints and disciplinary actions against dentists, as well as increasingly complex ethical dilemmas and regulatory controls.

The most common reasons for dentists calling the helpline in 1999 were for

\section{Make tax affairs more interesting}

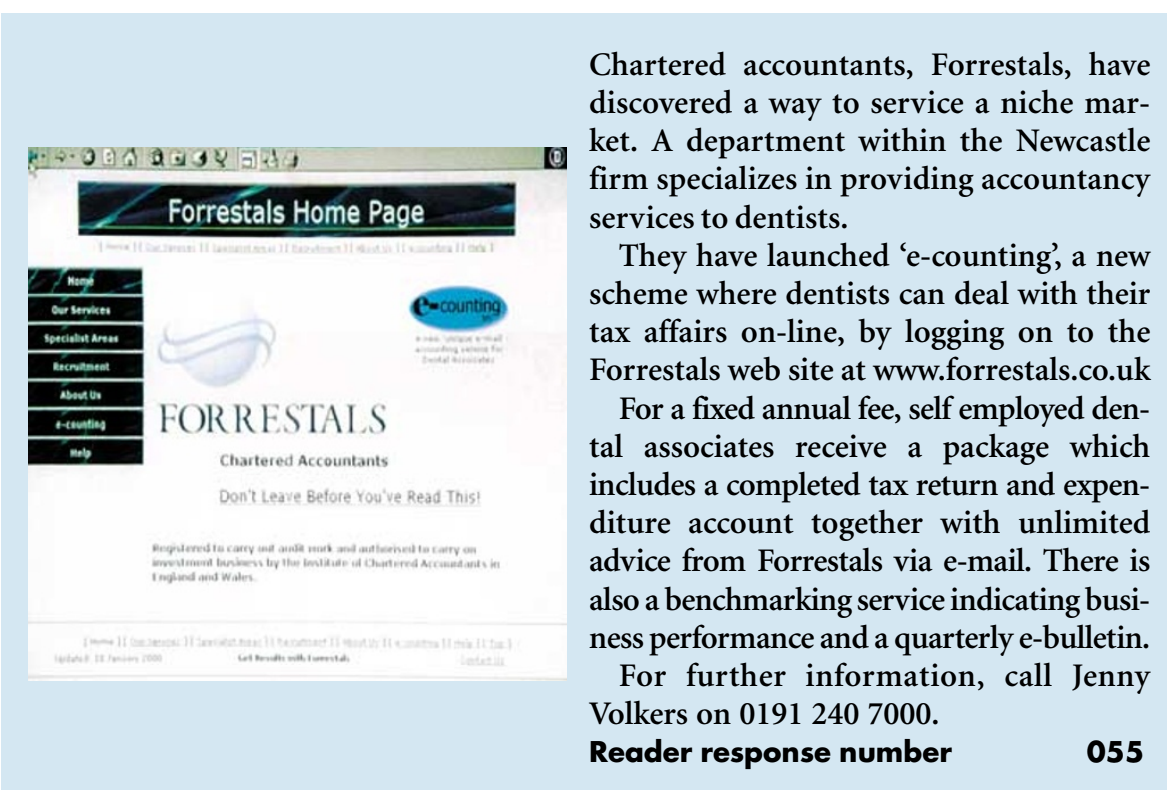

advice on:

- How to respond to a patient dissatisfied with treatment or service.

- What to do about financial disputes with patients arising from problems with treatment.

- Tooth bleaching

- Disclosure of clinical records and how long notes should be retained.

- General anaesthesia.

For further information please contact Dawn Boyall on 02074673107.

Reader response number:

057

\section{Dentalserve.net}

Dentalserve.net is - the company claim the first internet service provider dedicated to the whole dental profession and is built by dental professionals.

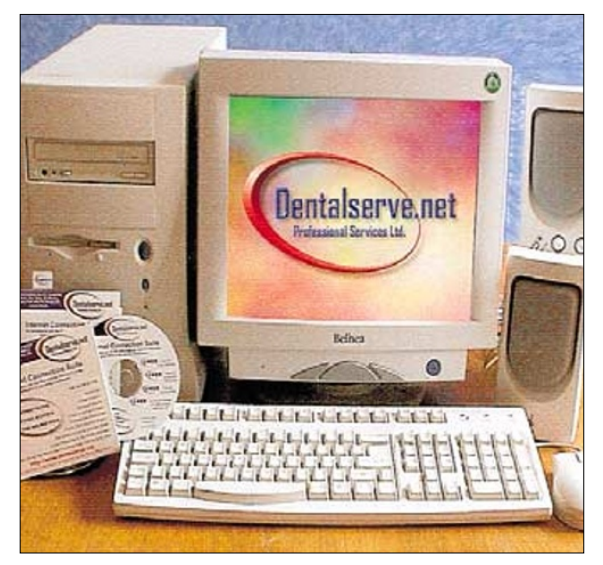

Within the site are situations vacant, discussion forums, new product launches, online auctions, professional resources and a dental mart for items wanted and on sale. In addition there are free unlimited e-mail addresses and $10 \mathrm{Mb}$ of free web space.

The public will be able to find a dentist in any particular area for free and, dentists will be able to promote their surgeries to a wide audience.

It is possible to place an advert on the net within minutes of posting to the website, which saves time when recruiting new staff.

For more information call

Dentalserve.net on 01474350300.

Reader response number:

061

\section{Mighty merger}

Two interactive knowledge resources, Health Communication Network (HCN) of Australia and Microinfo of Hampshire have recently merged.

Microinfo is a provider of professional knowledge, both via the internet and CDroms. Microinfo director, Roy Selwyn, claims that:

'Microinfo provides one of the largest collections of online and interactive information libraries and databases in Europe.'

$\mathrm{HCN}$ is an Australian provider of medical information and management tools, providing access to health information libraries and searchable databases.

For HCN, the new venture provides an opportunity to expand into the wide range of professional knowledge managed by Microinfo.

The company plans to apply its knowledge of on-line information management 
and delivery to the range of business needs met by Microinfo, including health and medicine, science, technology, commerce and other professions.

Call Roy Selwyn at Microinfo on 01420 86848 or Allison Hartman at HCN on 0061299066633.

Reader response number:

058

\section{DIY website}

Shop in a Box, Ardeo claim, is easy to use computer software that allows you to build a fully functional e-commerce website - even if you have limited computer knowledge. Connected to the internet, you can be ready to sell goods and services and accept payments securely in under an hour.

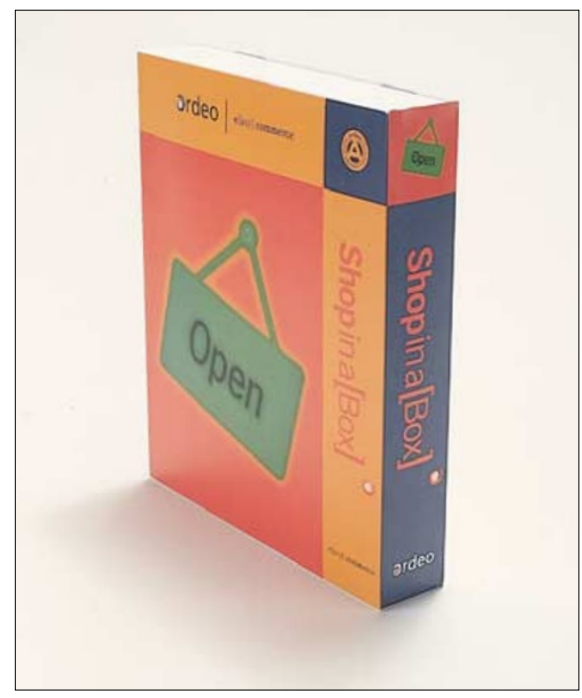

Shop in a Box is a fast and cheap way of opening a virtual shop. All you need to do is:

- Enter product and service details: Add descriptions, prices, associated pictures and images. Enter delivery, warranty, support information and staff contact details.

- Pick a layout for the store/site from the style gallery (artwork, catalogues, brochures or magazine templates) to give the website a professional look.

- Connect to the internet, click the 'publish changes' button and view the website. The shop is now on the internet and open for business. Shop in a Box costs just $£ 299$ with a monthly service

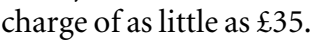

For more details, call Jessica on 020 89486611.

Reader response number:

\section{The future is here!}

E-academy is working in association with the Eastman Dental Institute to stream interactive programmes and live lectures directly to the home or practice of every dentist in the UK, via their computer, and in the future, through the television as well.

One-to-one training in any location is now a reality and for the first time every

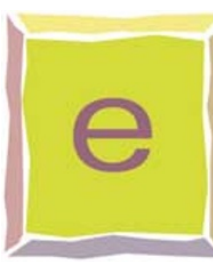
dentist in the UK will have personal access to the expertise of the world's leading dental specialists.

However, unlike watching the material from a academy compact disc, the content is streamed in real time into the dentists' computer, which means watching can be validated, responses logged and can therefore count towards verifiable continuing professional development hours. Each subscriber's viewing records can be maintained on a database until it is time to submit their mandated hours.

E-academy will be working closely with the Eastman Dental Institute to ensure the programme content is up-to-the-minute. The company has also linked up with t-dental.com who are poised to equip every dental practice in the UK with their computer hardware and software requirements.

Access to e-academy is though an annual subscription which gives dentists access to 15 hours of verifiable CPD.

For more information e-mail marc@keep-up-to-date.com or call 020 84450365.

Reader response number: $\quad 060$

\section{Lap-top luxury}

Advanced Healthcare Imaging Ltd has expanded its product portfolio to include the Dexis Direct Digital Radiography System.

With Dexis, the electronics are contained within a PCMCIA card that enables instant

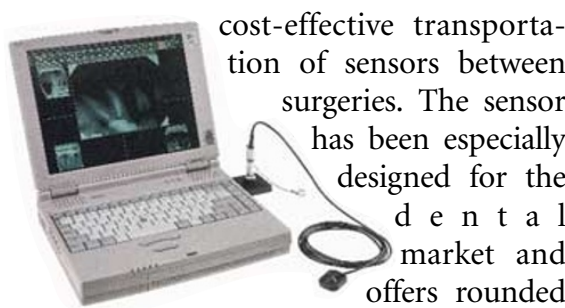
edges for maximum comfort.

The company claim that the Dexis System is the only system currently available that can be operated directly from a laptop computer. The software provided allows export of images to floppy disk, which can be viewed from any pc, as well as e-mail facilities to allow the electronic transmission of images.

For information, Freefone 08003281 605.

Reader response number:

061 